\title{
Efficacy of the essential oil of Origanum glandulosum Desf against skin infections With PVL-producing Staphylococcus aureus strains in mice
}

KHADIR Abdelmounaïm ${ }^{1}$, BENDAHOU Mourad ${ }^{* 1}$, BENBELAÏD Fethi ${ }^{1}$, GHELLAÏ Lotfi ${ }^{1}$, ABDOUNE Mohamed Amine ${ }^{1}$, BELLAHSENE Chafika ${ }^{1}$, ZENATI Fatima ${ }^{1}$, ABDELOUAHID Djamel Eddine ${ }^{1}$, MUSELLI Alain ${ }^{2}$, PAOLLINI Julien ${ }^{2}$, DESJOBERT Jean-Marie ${ }^{2}$ and COSTA Jean ${ }^{2}$

${ }^{1}$ Laboratory of Applied Microbiology in Food, Biomedical and Environment (LAMAABE), Department of Biology, Faculty of Nature and Life, Earth and Universe Sciences, AboubekrBelkaïd University of Tlemcen, 13000 Tlemcen, Algeria.

${ }^{2}$ Université de Corse, Equipe Chimie des Produits Naturels, UMR-CNRS 6134, Quartier Grossetti,

BP 52, 20250 Corti, France.

Accepted 3 May, 2013

\begin{abstract}
Skin and soft tissue infections (SSTI) caused by staphylococcal toxins including Panton-Valentine leukocidin (PVL) have increased these last years. Treatment of these complicated infections is often difficult. The search for new methods and new antimicrobial substances is necessary. Natural products such as essential oils appear among the possible solutions. The objective of our work was to prove the effectiveness of treatment of these infections with essential oils in vivo on Wistar rats; we have chosen the oil of Origanum glandulosum from Algeria to perform this treatment because of its antiseptic properties. The treatment was done on infections induced in Wistar rats using PVL producing Staphylococcus aureus strain isolated from Tlemcen University Hospital. The results of our experiment have shown a significant decrease in the number of colonies collected from rats treated by the concentrations of 1 and $5 \%$ of 0 . glandulosum essential oil. The treatment of skin infections especially wounds caused by PVL positive $S$. aureus is possible with the essential oil of 0 . glandulosum which seems to be effective in eradicating the germ from infected wounds.
\end{abstract}

Key words: PVL-producing, Staphylococcus aureus, essential oil, skin infection, Origanum glandulosum.

\section{INTRODUCTION}

Skin and soft tissue infections (SSTI) are among the human diseases that have shown an alarming increase in the prevalence in recent years (Kaltsas et al., 2011). These infections are due to a variety of species of microorganisms among which Staphylococcus aureus is classified primarily (May et al., 2009). This species colo- nizes the skin and wounds of patient by forming a biofilm that allows this organism to persist in this condition and produce toxins (Percival et al., 2011) of several types such as exfoliatins, toxic shock syndrome toxin TSST-1, enterotoxins and Panton- Valentine leukocidin (PVL), that is why this bacterium is among the spe- 
cies that contain the largest number of virulence factors (Archer 1998).

PVL is associated with several skin diseases such as furunculosis (Del Giudice et al., 2011), cellulitis and skin abscess (del Giudice et al., 2009). It kills human polymorphonuclear leukocytes and is expressed at high toxic levels in human skin abscess (Badiou et al., 2008) and in necrotizing pneumonia (Labandeira-Rey et al., 2007). It is encoded by two genes, lukF-PV and lukS-PV which are transported horizontally by phages such as ФSLT (Sachiko et al., 2001) and secreted by methicillinsusceptible $S$. aureus strains (MSSA) and methicillin-resistant strains (MRSA) circulating in community and hospital (Lo et al., 2009; Varshney et al., 2010). This toxin is sometimes produced at high level by methicillinsusceptible MSSA strains (Varshney et al., 2010). In vivo studies in mice have shown a positive correlation between the production of PVL and the damage of the infected wounds (Varshney et al., 2010). Treatment of such infections continues to report therapeutic failures (Nichols 1999) because of its complications that may develop kidney failure (Pereira et al., 2012). PVL may be responsible for serious infections, especially in children in neonatology (Dunlop and Eadie, 2011), but also in cases of infections with multidrug-resistant germs (Nichols 1999). Efficient and prompt treatment does not exist until now (Gillet et al., 2011). There is a need of a more convenient and less expensive treatment mainly during cutaneous infections with PVL-producing MSSA (Halcon and Milkus, 2004).

The search for new substances to better treat these infections is necessary (Nathwani, 2009). Natural products of plant origin such as essential oils seem to be a good way to replace the treatments with antibiotics (Warnke et al., 2009) since they constitute a reservoir of antimicrobial molecules (Edris, 2007), but also for their ability to inhibit virulence factors of $S$. aureus (Qiu et al., 2011) and quorum sensing (Szabo et al., 2010) in addition to their anti-biofilm effect (Quave et al., 2008), wound healing activity (Ipek et al., 2012) and stimulating the immune system response (Standen and Myers, 2004).

Origanum glandulosum, is a spontaneous (Basli et al., 2012) and endemic (Quezel and Santa 1963) plant of Northern Algeria, belonging to the Lamiaceae family. $\mathrm{O}$. glandulosum is an interesting medicinal plant known by various therapeutic properties (Basli et al., 2012) namely the treatment of whooping cough, cough, fever and bronchitis (Sari et al., 2006), and its antiseptic use traditionally on skin used in baths (Belhattab et al., 2005). The antimicrobial activity of $O$. glandulosum essential oil was studied in previous studies; Bekhechi et al. (2008) have demonstrated the antimicrobial activity of $O$. glandulosum essential oil against various species of fungi and bacteria including three $S$. aureus strains, two reference strains ATCC 601 and ATCC 43866 and one clinical strain. The results show a strong antistaphylococcal activity with inhibition diameters ranging from 22 to $25 \mathrm{~mm}$ with the vincent method (Bekhechi et al., 2008). In the other hand, Bendahou et al. (2008) tested $O$. glandulosum essential oil obtained by hydrodstillation and microwave extraction on microbial species; among them, one strain was $S$. aureus. The two types of essential oil showed strong activity against $S$. aureus strain with an inhibition diameter of $23 \mathrm{~mm}$ (Bendahou et al., 2008).

In the absence of in vivo treatment with essential oils of infections due to $S$. aureus toxin-producing strains, specifically the Panton-Valentine leukocidin, we had the idea to make this work which involves inducing skin infection in mice with PVL-producing $S$. aureus strains, then making a treatment with essential oil obtained from an Algerian medicinal plant, O. glandulosum.

\section{MATERIALS AND METHODS}

\begin{abstract}
Materials
Bacterial strains

One $S$. aureus strain was selected from a number of clinical strains to be used in this work based on its PVL toxin production. This strain was isolated from skin infections at University Hospital of Tlemcen. The identification was realized with API Staph gallery, BioMérieux, Marcy-l'Étoile, France. This identification was confirmed using matrix-assisted laser desorption ionization time-of-flight mass spectrometry (MALDITOF-MS) (BrukerDaltonics, Bremen, Germany) (Seng et al., 2010).
\end{abstract}

\section{Animals}

Twelve (12) Wistar rats of weight between 20 and $22 \mathrm{~g}$ adult males were used for this experiment. The strains were provided by Pasteur Institute of Algeria. The rats were left for $48 \mathrm{~h}$ before the experiment as an acclimatization phase; water and feed were provided to rats. Experiments on these animals were done according to the European decree on ethical rules Directive 86/609/EEC. The rats were divided into two groups: the first group consisted of six rats. Five rats suffered an infection and one uninfected rat represents the negative control. Among the infected in this group, one rat was used as a positive control. The second group suffered the same conditions except for the positive control, which in addition to the infection; this rat was exposed to a treatment with paraffin oil (BIOCHEM Chemopharma) alone.

The negative control of the first group has neither been infected nor undergone incisions and it was treated with essential oil diluted to $5 \%$ in paraffin; while, the negative control of the second group underwent incisions but was not infected.

\section{Plant materials}

The plant material was harvested in full flowering stage during June 2011 in Sebdou located in south of Tlemcen (Algeria, 34 $69^{\prime} 41.32 "$ 
to $\left.1^{\circ} 31^{\prime} 70.72 "\right)$. The species identification was confirmed by the Laboratory of Botany, University of Tlemcen. A specimen was deposited at the herbarium of this laboratory under code Lb.06.

Obtaining essential oil was made by hydrodistillation for $3 \mathrm{~h}$ using a Clevenger-type apparatus. The oil obtained was dehydrated by anhydrous sodium sulfate and then kept at a temperature of $4^{\circ} \mathrm{C}$ and protected from the effect of light until analysis.

\section{Methods}

\section{PCR amplification}

The search for the $P V L$ gene was made by real time polymerase chain reaction (PCR) using a StratageneMx 3000 appartus and TaqMan probe primers as previously described (Francois et al., 2004).

F> (5'-AAAATGCCAGTGTTATCCAGAGGTA-3')

R> (5'-TTTGCAGCGTTTTGTTTTCG-3')

Prob (5'-CTTCAATCCAGAATTTATTGGTGT-3').

\section{Induction of infection}

The rats used for the experiment had a local anesthesia (Suntar et al., 2011). Then, they were been shaved at the back dorsal part with an electric razor and cleaned with $70 \%$ ethanol; three superficial incisions were made using sterile surgical blade (Varshney et al., 2010). Then $20 \mu \mathrm{l}$ of the bacterial suspension of PVL positive S. aureus at $10^{7} \mathrm{CFU} / \mathrm{ml}$ was introduced directly into the incisions in the wounds for a development of infection with PVLpositive $S$. aureus. Then, each rat was isolated in a separate cage to avoid contamination between rats. Cages were subjected to regular cleanings with detergents.

\section{GC/MS analysis}

The analysis of the essential oil of $O$. glandulosum was performed on an Auto system Perkin Elmer GC-type apparatus with standard non polar/polar capillary columns coupled with a mass spectrometer Perkin Elmer Turbo Mass detector.

\section{Susceptibility tests}

The susceptibility of the strain used in this experiment to the essential oil was evaluated by the disk method of Bauer and Kirby. In short, a culture of $18 \mathrm{~h}$ on BHIB (brain heart broth, CondaPronadisa $^{\mathrm{TM}}$, Spain) was standardized to $10^{8} \mathrm{CFU} / \mathrm{ml}$, then inoculated by swabbing the surface of Mueller-Hinton agar (FlukaBioChemika, Spain) according to the recommendation of CLSI 2010. Sterile filter paper disks (Whatman No. 2) with $6 \mathrm{~mm}$ diameter were impregnated with $2 \mu \mathrm{l}$ of essential oil, and then the disks were placed on the surface of Mueller-Hinton medium. The minimum inhibitory concentration was been also calculated by the method of microdilution (Mann and Markham, 1998). Susceptibility tests were made in triplicate.

\section{Treatment}

Treatment with essential oil of O. glandulosum Desf., has been made in preparing four oil concentrations in the pure paraffin (BIOCHEM Chemopharma) (5, 1, 0.5 and $0.25 \%$ ).

The treatment was applied to the infected rats by spreading 500 $\mu \mathrm{l}$ of the solution directly on the infected wounds. Before each treatment, a swabbing is performed then the swab is inserted into a tube of $5 \mathrm{ml}$ of sterile physiological saline while the solution was vortexed. For each sample, four successive dilutions were made, $100 \mu \mathrm{l}$ of each dilution was then deposited on to mannitol salt agar (Merck). The inoculation was then performed by a sterile swab and incubation was for $24 \mathrm{~h}$ at $37^{\circ} \mathrm{C}$ for enumeration. The colony forming unit (CFU) values determination was determined according to Petrou et al. (2012). After incubation, the colony count was done directly on agar plate for dilutions which have colonies numbers between 30 and 300 colonies, and then the number of colony was expressed in decimal logarithm. Standard deviation was calculated with the difference between the two replication values of CFU of each dilution.

\section{RESULTS}

Identification of $S$. aureus strain used in this experiment by API Staph bioMerieux gave a biotype 6726153 . This identification was confirmed by using MALDI-TOF MS with a score greater than 2. The results of PCR amplification have shown that the strain used in this work was a PVL-positive strain as shown in Figure 1 among a number of clinical strains. This strain was selected for the experiment.

The extraction of our oil by hydrodistillation gave a yield of $5 \%$. O. glandulosum essential oil is rich in thymol (42.3\%), p-cymene (17.6\%) and $\gamma$-terpinene (25.9\%) (Table 1). The antibacterial activity of our oil to PVLpositive strain tested in this experiment gave high inhibition diameter of $42 \mathrm{~mm}$ using only $2 \mu \mathrm{l}$ of oil, resulting to extreme antimicrobial activity (Ponce et al., 2003) and an MIC of $0.0625 \mu \mathrm{l} / \mathrm{ml}$.

All rats have developed an infection after $24 \mathrm{~h}$ of incubation. The infection was characterized by production of pus around the incision. No mortality was observed, and no sign of inflammation or susceptibility to oil was observed for the negative control.

The treatment of skin infections by PVL-positive $S$. aureus in rats with Origanum glandulosum has shown a decrease in the number of CFU for all the concentrations used (Figure 2). After the first treatment, there was a stability in the number of colonies for concentrations $0.25,0.5$ and $1 \%$, while for the concentration of $5 \%$, a slight decrease was observed after the first treatment, whereas the second treatment has shown a significant reduction in number of CFU for the concentration of $5 \%$ by $0.93 \log _{10}$ and a slight decrease for $1 \%$ concentration. For the third treatment, a severe reduction of $\mathrm{CFU}$ for the concentration of $5 \%$ by $1.8 \log _{10}$ and for $1 \%$ by $1.06 \log 10$ was observed; also, a remarkable decrease in the concentra- tions 0.5 and $0.25 \%$ which have shown a stability of CFU in the first 


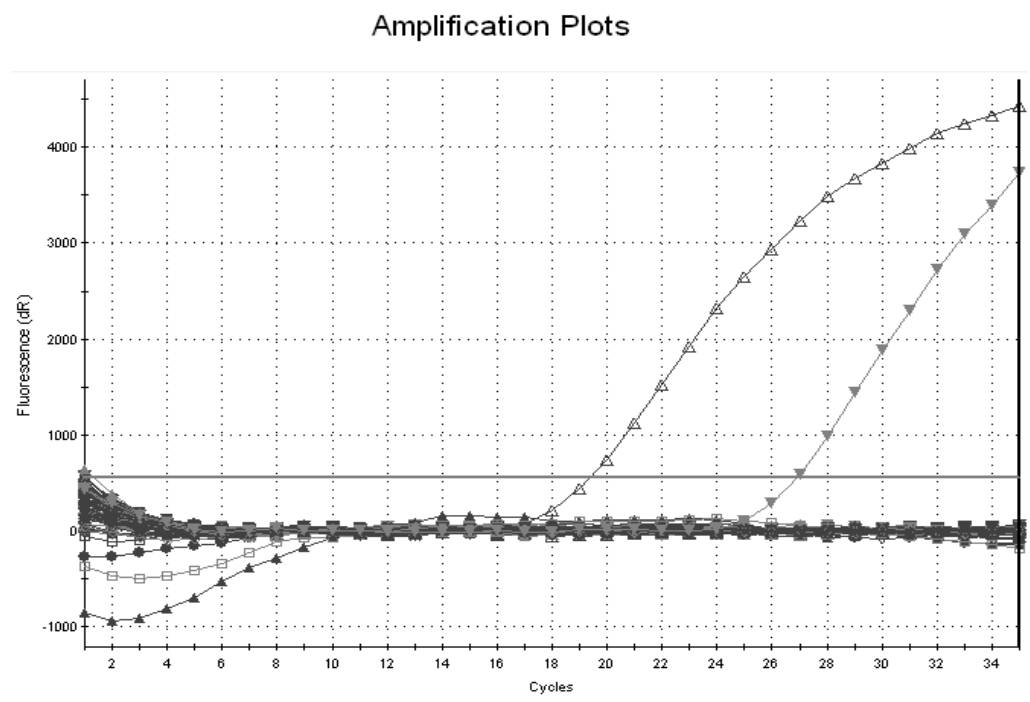

Figure 1. Real-time PCR amplification of PVL-positive Staphyloeoccus aureus: $\triangle$, Positive control; $\nabla$ PVL-positive strain.

Table 1. The major compounds of Origanum glandulosum Desf.

\begin{tabular}{lccc}
\hline Compound & Rla & Rlp & $\%$ \\
\hline p-Cymene & 1011 & 1268 & 17.6 \\
Limonene & 1020 & 1199 & 0.9 \\
Y-Terpinene & 1047 & 1243 & 25.9 \\
Thymol & 1266 & 2189 & 42.3 \\
Carvacrol & 1278 & 2219 & 02.3 \\
Monoterpene hydrocarbons & & & 52.2 \\
Oxygenated monoterpenes & & & 45.7 \\
\hline
\end{tabular}

Rla and Rip are retention index on RTX-1 apolar column and RT-Wax polar column, respectively

two treatments.

In the fourth treatment, we clearly saw an eradication of the germ from the infection sites for $5 \%$ concentration and a very substantial reduction in the concentration of $1 \%$ by $1.28 \log _{10}$.

The fifth treatment reveals a total eradication of CFU for the concentration of $5 \%$ while a dramatic decrease in the number of CFU by $1.69 \log 10$ and $1.3 \log 10$ for the concentrations 1 and $0.5 \%$ respectively, while for the two positive controls no decrease was observed and the number of CFU was stable during the treatment days.

\section{DISCUSSION}

From these results, we can say that treatment with a $5 \%$ concentration allows a rapid eradication of the organism in five days but the concentration $1 \%$ allows a considerable reduction of infection with $1.69 \log _{10}$ in five days of treatment, while the positive control have shown a stable number of CFU which confirms the strong colonization of the site of infection by this pathogen in the absence of treatment (Figure 2). We can deduce that this treatment with the essential oil is concentration dependent. We can also say that the concentrations in the range between 1 and $5 \%$ may be effective in eradicating this organism producing PVL toxin, this efficiency is due to the low MIC of this strain to our essential oil which has a value of $0.0625 \mu \mathrm{l} / \mathrm{ml}$.

If we compare our results with those obtained with reference molecules such as mupirocin tested by Gisby and Bryant (2000), we will notice that O. glandulosum oil has a stronger effect. In the study performed by Gisby and Bryant (2000); the autors demonstrated that mupirocin cream at $2 \%$ reduces CFU from $7.23 \log _{10}$ to $2.51 \log _{10}$ as a reduction of $65.28 \%$ on the fifth day of treatment. While $O$. glandulosum oil only in concentration of $1 \%$ gave a reduced number of CFU from $2.19 \log _{10}$ to $0.5 \log _{10}$ as a reduction of $77.16 \%$ in the fifth day of treatment. This confirms the effectiveness of $\mathrm{O}$. glandulosum oil treatment. In addition, there is an urgent need to look for other substances to replace mupirocin because of the spread of $S$. aureus resistant strains to this molecule (Park et al., 2012).

In our work, we demonstrated treatment of skin infection produced by PVL-positive $S$. aureus with essential oil from O. glandulosum Desf. Our choice of the PVL-positive strain of $S$. aureus was based on ability to cause more serious infections in mice than PVL- 


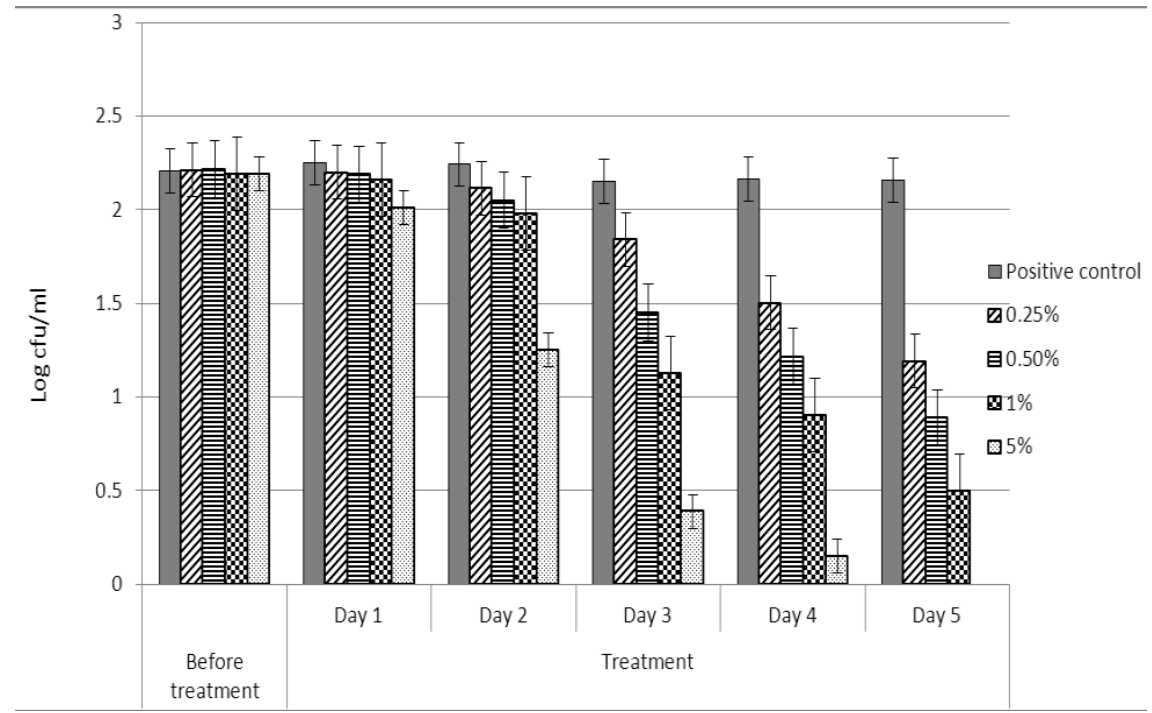

Figure 2. The effect of essential oil on reducing the number of CFU from the infected wounds by PVL-producing Staphylococcus aureus.

negative strains (Varshney et al., 2010) to prove the efficacy of this treatment against infections complicated and difficult to treat. Our oil has allowed a good eradication of the number of CFU at concentrations higher than $1 \%$. This in vivo activity is mainly due to content in thymol (42.3\%) which has the highest toxic activity against the membrane of $S$. aureus by inducing permeability (Cristani et al., 2007) and acts in the same manner in MRSA and MSSA (Nostro et al., 2004). This activity is also due to $y$-terpinene and $p$ cymene which have significant amount of 25.9 and $17.6 \%$, respectively and are known for their cytotoxic activity against Gram-positive and Gram-negative bacteria (Cristani et al., 2007). The mechanism of action of these three monoterpenes is due to penetration into the plasma membrane and the disruption of lipid fractions and other membrane functions (Cristani et al., 2007).

S. aureus colonizes the wounds in the form of a biofilm that is not treatable with antibiotics (Katsuyama et al., 2005) and only the action of polymorphonuclear leukocytes which is capable of destroying this biofilm (Akiyama et al., 2002). The problem with infection by PVL-positive $S$. aureus is that leukocytes are destroyed by the PVL which explains the complication of these infections being difficult to treat. Our results show that the essential oil of $O$. glandulosum Desf., has a remarkable effect on the eradication of this PVL-producing germ in infected wounds. These results leave us to think that this essential oil that has been used medicinally for several therapeutic purposes in Algeria can be a good solution to fight against skin infection due to PVL-producing $S$. aureus. For this purpose, we assume that the herbal treatment with essential oils is possible in the form of an ointment or lotion and can be an alternative treatment to antibiotics in infections difficult to treat such as SSTI caused by PVL-producing S. aureus.

\section{ACKNOWLEDGEMENT}

We would like to thank ROLAIN Jean-Marc from « Unité de Recherche sur les Maladies Infectieuses et Tropicales Émergentes (URMITE) Marseille » for Real time PCR amplification and MALDI-TOF MS identification.

\section{REFERENCES}

Akiyama H, Huh W-K, Yamasaki O, Oono T, Iwatsuki K (2002). Confocal laser scanning microscopic observation of glycocalyx production by Staphylococcus aureus in mouse skin: does $S$. aureus generally produce a biofilm on damaged skin? Br. J. Dermatol.147: 879-885.

Archer GL (1998). Staphylococcus aureus: A Well-Armed Pathogen. Clin. Infect. Dis. 26: 1179-1181.

Badiou COD, Croze M, Gillet Y, Dohin B, Slayman D H, Allaouchiche B, EtienneJ, VandeneschF, Lina G (2008). Panton-Valentine leukocidin is expressed at toxic levels in human skin abscesses. Clin. Microbiol. Infect. 14: 1173-1186.

Basli A, Chibane M, Madani K, Oukil N (2012). Activité antibactérienne des polyphénols extraits d'une plante médicinale de la flore d'Algérie: Origanum glandulosum Desf. Phytothérapie 10: 2-9.

Bekhechi C, Atik-Bekkara F, Abdelouahid DE (2008). Composition et activité antibactérienne des huiles essentielles d'Origanum glandulosum d'Algérie. Phytothérapie 6: 153-159.

Belhattab R, Larous L, Figueiredo AC, Santos PAG, Barroso JG, Pedro LG (2005). Origanum glandulosum Desf. grown wild in Algeria: 
essential oil composition and glycosidic bound volatiles. Flavour Fragr. J. 20:209-212.

Bendahou M, Muselli A, Grignon-Dubois M, Benyoucef M, Desjobert JM, Bernardini A-F, Costa J (2008). Antimicrobial activity and chemical composition of Origanum glandulosum Desf. essential oil and extract obtained by microwave extraction: Comparison with hydrodistillation. Food Chem.106:132-139.

Cristani M, D'Arrigo M, Mandalari G, Castelli F, Sarpietro MG, Micieli DVV, Bisignano G, Saija A, Trombetta D (2007). Interaction of Four Monoterpenes Contained in Essential Oils with Model Membranes: Implications for Their Antibacterial Activity. J. Agric. Food Chem. 55:6300-6308.

Del Giudice P, Bes M, Hubiche T, Blanc V, Roudiere L, Lina G, Vandenesch F, Etienne J (2011). Panton-Valentine leukocidinpositive Staphylococcus aureus strains are associated with follicular skin infections. Dermatology 222:167-170.

del Giudice P, Blanc V, de Rougemont A, Bes M, Lina G, Hubiche T, Roudiere L, Vandenesch F, Etienne J (2009). Primary skin abscesses are mainly caused by Panton-Valentine leukocidinpositive Staphylococcus aureus strains. Dermatology 219:299-302.

Dunlop RL, Eadie P (2011). Idiopathic neonatal necrotising fasciitis caused by community-acquired MSSA encoding Panton Valentine Leukocidin genes. J. Plast Reconstr. Aesthet. Surg. 64: 1522-1524.

Edris AE (2007). Pharmaceutical and Therapeutic Potentials of Essential Oils and Their Individual Volatile Constituents: A Review. Phytother. Res. 21:308-323.

Francois $\mathrm{P}$, Renzi G, Pittet D, Bento M, Lew D, Harbarth S, Vaudaux P, Schrenzel J (2004). A novel multiplex real-time PCR assay for rapid typing of major staphylococcal cassette chromosome mec elements. J. Clin. Microbiol. 42:3309-3312.

Gillet $\mathrm{Y}$, Dumitrescu O, Tristan A, Dauwalder O, Javouhey E, Floret D, Vandenesch F, Etienne J, Lina G (2011). Pragmatic management of Panton-Valentine leukocidin-associated staphylococcal diseases. Int. J. Antimicrob. Agents 38:457-464.

Gisby J, Bryant J (2000). Efficacy of a New Cream Formulation of Mupirocin: Comparison with Oral and Topical Agents in Experimental Skin Infections. Antimicrob. Agents Chemother. 44:255-260.

Halcon L, Milkus K (2004). Staphylococcus aureus and wounds: A review of tea tree oil as a promising antimicrobial. Am. J. Infect. Control 32:402-408.

Ipek SIT, Osman U, Hikmet K, Esra KA (2012). Appraisal on the wound healing and anti-inflammatory activities of the essential oils obtained from the cones and needles of Pinus species by in vivo and in vitro experimental models. J. Ethnopharmacol.139:533- 540.

Kaltsas A, Guh A, Mediavilla JR, Varshney AK, Robiou N, Gialanellia P, Henry M, Levi MH, Fries BC (2011). Frequency of panton-valentine leukocidin-producing methicillin-sensitive Staphylococcus strains in patients with complicated skin and soft tissue infection in bronx, new york. J. Clin. Microbiol. 49:2992-2995.

Katsuyama M, Ichikawa H, Ogawa S, Ikezawa Z (2005). A novel method to control the balance of skin microflora. Part 1. Attack on biofilm of Staphylococcus aureus without antibiotics. J. Dermatol. Sci. 38:197-205

Labandeira-Rey M (2007). Staphylococcus aureus Panton-Valentine leukocidin causes necrotizing pneumonia. Science 315:1130-1133.

Lo WT, Tang CS, Chen SJ, Huang CF, Tseng MH, Wang CC (2009). Panton-Valentine leukocidin is associated with exacerbated skin manifestations and inflammatory response in children with community-associated staphylococcal scarlet fever. Clin. Infect. Dis. 49:e69-75

Mann CM, Markham JL (1998). A new method for determining the minimum inhibitory concentration of essential oils. J. Appl. Microbiol. 84:538-544.

May A, Stafford R, Bulger E, Heffernan D (2009). Treatment of Complicated Skin and Soft Tissue Infections. Surg. Infect. 10(5):467499.

Nathwani D (2009). New antibiotics for the management of complicated skin and soft tissue infections: are they any better? Int. J. Antimicrob.
Agents 34(S1):S24-S29.

Nichols R (1999). Optimal treatment of complicated skin and skin structure infections. J. Antimicrob. Chemother.44:19-23.

Nostro A, Blanco AR, Cannatelli MA, Enea V, Flamini G, Morelli I, Sudano Roccaro A, Alonzo V (2004). Susceptibility of methicillinresistant staphylococci to oregano essential oil, carvacrol and thymol. FEMS Microbiol. Lett. 230:191-195.

Park SY, Kim SM, Park SD (2012). The prevalence, genotype and antimicrobial susceptibility of high- and low-level mupirocin resistant methicillin-resistant Staphylococcus aureus. Ann. Dermatol. 24: 32 38.

Percival S, Emanuel C, Cutting K, Williams DW (2011). Microbiology of the skin and the role of biofilms in infection. Int. Wound J. 9:14-32.

Pereira G, Guevara M, Fagundes C, Sola E, Rodriguez E, Fernandez J, Pavesi M, Arroyo V, Gines P (2012). Renal failure and hyponatremia in patients with cirrhosis and skin and soft tissue infection. A retrospective study. J. Hepatol. 56:1040-1046.

Petrou S, Tsiraki M, Giatrakou V, Savvaidis IN (2012). Chitosan dipping or oregano oil treatments, singly or combined on modified atmosphere packaged chicken breast meat. Int. J. Food Microbiol. 156:264-271.

Ponce AG, Fritz R, del Valle C, Roura SI (2003). Antimicrobial activity of essential oils on the native microflora of organic Swiss chard. LWT Food Sci. Technol. 36:679-684.

Qiu J, Wang J, Luo H, Du X, Li H, Luo M, Dong J, Chen Z, Deng X (2011). The effects of subinhibitory concentrations of costus oil on virulence factor production in Staphylococcus aureus. J. Appl. Microbiol. 110:333-340.

Quave CL, Plano LR, Pantuso T, Bennett BC (2008). Effects of extracts from Italian medicinal plants on planktonic growth, biofilm formation and adherence of methicillin-resistant Staphylococcus aureus. J. Ethnopharmacol. 118:418-428.

Quezel P, Santa S (1963). Nouvelles flores de l'Algerie et des regions desertiques meridionales. T. II, CNRS, Paris, France.

Sachiko NJK, Jun-ichi C, Yves P, Sophie J, Jerome EYK (2001). Phage conversion of Panton-Valentine leukocidin in Staphylococcusv aureus: molecular analysis of a PVL-converting phage, $\Phi$ SLT. Genes 268:195-206.

Sari M, Biondi DM, Kaâbeche M, Mandalari G, D'Arrigo M, Bisignano G, Saija A, Daquino C, Ruberto G (2006). Chemical composition, antimicrobial and antioxidant activities of the essential oil of several populations of Algerian Origanum glandulosum Desf. Flavour Fragr. J. 21: 890-898

Seng P, Rolain J-M, Fournier PE, La Scola B, Drancourt M, Raoult D (2010). MALDI-TOF-mass spectrometry applications in clinical microbiology. Future Microbiol. 5:1733-1754.

Standen M, Myers S (2004). The roles of essential oils in the modulation of immune function and inflammation: survey of aromatherapy educators. Int. J. Aromather. 14:150-161.

Suntar I, Akkol EK, Keles H, Oktem A, Baser KH, Yesilada E (2011). A novel wound healing ointment: a formulation of Hypericum perforatum oil and sage and oregano essential oils based on traditional Turkish knowledge. J. Ethnopharmacol. 134:89-96.

Szabo MA, Varga GZ, Hohmann J, Schelz Z, Szegedi E, Amaral L, Molnar J (2010). Inhibition of quorum-sensing signals by essential oils. Phytother. Res. 24:782-786.

Varshney AK, Martinez LR, Hamilton SM, Bryant AE, Levi MH, Gialanella P, Stevens DL, Fries BC (2010). Augmented production of Panton-Valentine leukocidin toxin in methicillin-resistant and methicillin-susceptible Staphylococcus aureus is associated with worse outcome in a murine skin infection model. J. Infect Dis. 201:9296.

Warnke PH, Becker ST, Podschun R, Sivananthan S, Springer IN, Russo PA, Wiltfang J, Fickenscher H, Sherry E (2009). The battle against multi-resistant strains: Renaissance of antimicrobial essential oils as a promising force to fight hospital-acquired infections. J. Craniomaxillofac Surg. 37:392-397. 